\title{
OFTALMOPLEGIA INTERNUCLEAR EM PACIENTE COM MIELOSE FUNICULAR
}

\section{J. Lamartine de Assis *}

\author{
LINEU C. FONSECA **
}

A oftalmoplegia internuclear é uma alteração da motricidade extrínseca ocular em que, no olhar lateral, a abdução de um ôlho é normal mas a adução do outro ôlho está ausente ou diminuída. No entanto, o músculo reto medial ( $R M)$ deficitário no olhar lateral, muitas vêzes é capaz de promover a adução normal do globo ocular na convergência e na estimulação do labirinto oposto com água fria ${ }^{1,7}$. Pode-se observar, com freqüência, nistagmo horizontal do ôlho abduzido. Têm sido referidos, também, nistagmos vertical e rotatório e, às vêzes, sintomas e sinais neurológicos resultantes de comprometimento de estruturas do tronco cerebral. As manifestações podem ser uni ou bilaterais e, nesta última situação, simétricas ou assimétricas.

A relativa raridade da síndrome de paralisia internuclear, sua possível relação com a neuranemia e as pesquisas eletromiográficas realizadas, justificam o registro do caso.

\section{OBSERVAÇÃO}

A. C. P., 60 anos de idade, sexo feminino, branca, registro H.C. 491.353, internada em 1-2-66 e reinternada em 12-12-66. História clínica iniciada 3 anos antes da última internação, com parestesias nos membros inferiores que se tornaram cada vez mais intensas e, ao mesmo tempo, dificuldade para deambular. Ulteriormente, surgiram parestesias nas extremidades distais dos membros superiores e impossibilidade de andar sem apoio. Antecedentes sem fatos digos de nota. Exame clínico-neurológico - Paciente obesa, afebril e normotensa. Nada de importante foi verificado no exame dos diferentes órgãos e aparelhos. O exame neurológico evidenciou uma sindrome sensitivo-motora decorrente de comprometimento dos cordões posterior e lateral da medula espinal e de nervos periféricos nos membros inieriores assim caracterizada: paraparesia crural com hipotonia e discreta redução da fôrça muscular; reflexos patelares e aquilianos exaltados; desordens da sensibilidade superficial com distribuição em bota; apalestesia e ataxia tipo sensitivo

Trabalho da Clínica Neurológica da Faculdade de Medicina da Universidade de São Paulo (Prof. Adherbal Tolosa), apresentado no XIV Congresso Brasileiro de Oftalmologia (São Paulo, 7 a 13 de setembro de 1967): * Docente-Livre; ** Médico-estagiário. 
nos membros inferiores; sinal de Romberg presente. O exame da motricidade extrínseca ocular revelou, ao olhar lateral para a direita, déficit da adução do ôiho esquerdo, que é mais intenso com a fixação do olhar em objeto distante (Fig. 1, D e E) e nistagmo horizontal do ôlho abduzido. Ao olhar lateral para a esquerda, o nistagmo do ôlho abduzido é menos acentuado e o déficit da adução do globo ocular direito só aparece, mesmo assim de modo discreto, ao fixar objeto distante (Fig. 1, B e C). Nistagmo vertical de ambos os olhos ao olhar para
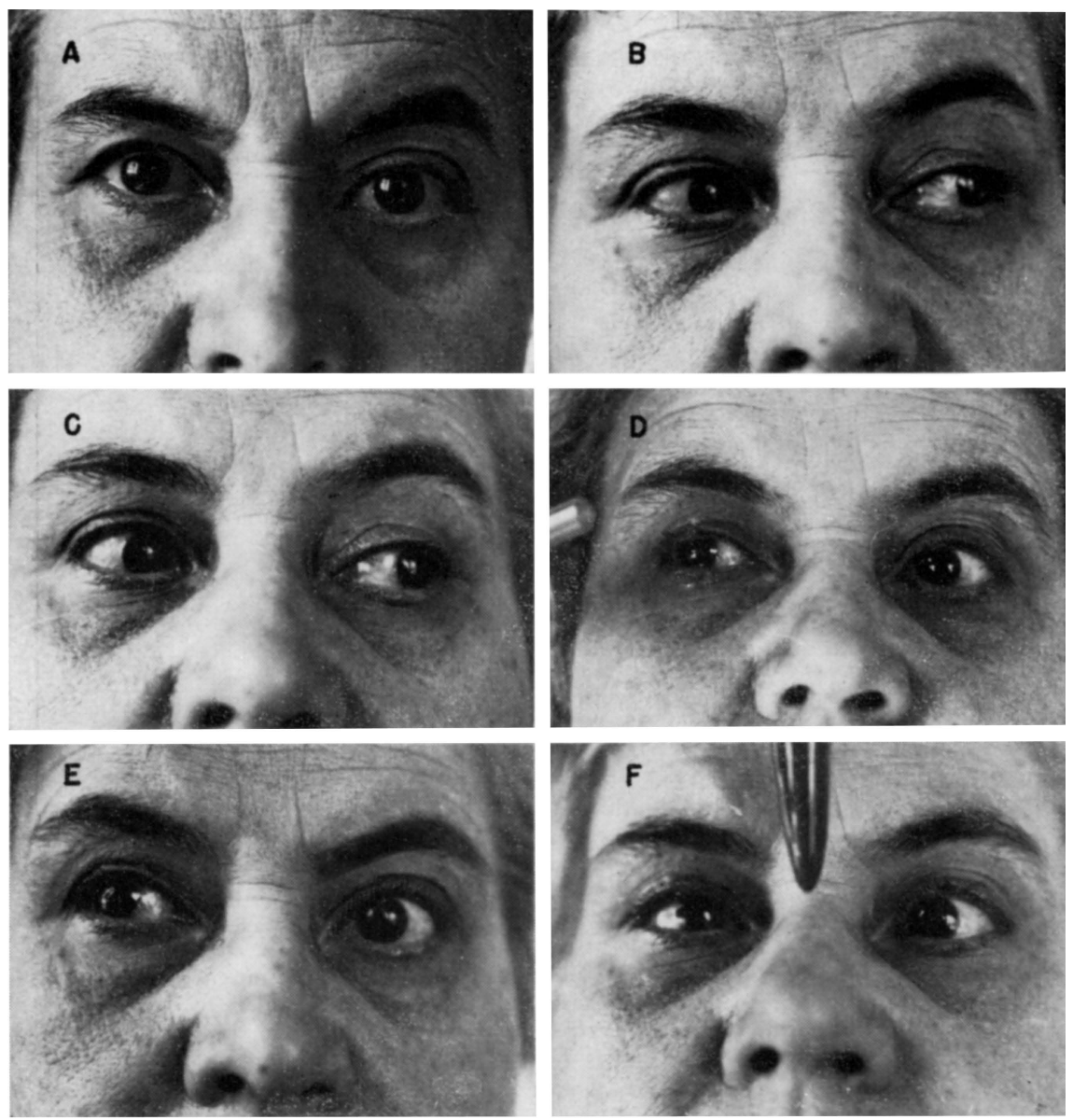

Fig. 1 Caso A.C.P. - Exame da motricidade extrinseca ocular: em A, olhos em posição primária $e$ olhar dirigido para longe; em $B$, olhar para a esquerda normal (fixação do olhar em objeto próximo); em $C$, olhar para a esquerda com limitação moderada da adução do ôlho direito (fixação do olhar em objeto afastado); em $D$, olhar para direita com limitação acentuada da adução do ôlho esquerdo (fixação do olhar em objeto próximo); em E, olhar para a direita com limitação riuito acentuada do ôlho esquerdo (fixação do olhar em objeto afastado); em $F$, reflexo de acomodação e convergência normal, sendo de notar a adução normal de ambos os olhos. $\hat{E}$ de notar que havia, de modo constante, nistagmo horizontal do ôlho abduzido e nistagmo vertical bilateral ao olhar para cima. 
cima. A pesquisa da convergência mostra adução normal dos dois lados (Fig. 1, ). Fundos oculares e campos visuais normais. Hipoacusia de percepção bilateral. Hiperreflexia vestibular direita. Exames complementares - Liquido cefalorraqueano por punçāo lombar normal. Absorção da vitamina $B_{12}$ radioativa marcada com ${ }^{57} \mathrm{Co}$ (método de Schilling) diminuida por falta do fator intrínseco. Teste do hitalog normal. Absorção de lipides normal. Glicemia em jejum normal. Exame hematologico normal. Electromiografia dos músculos reto mediais: não aparecem sinais electromiográficos de paralisia neurogênica nem de afecção muscular pròpriamente dita (fig. 2).
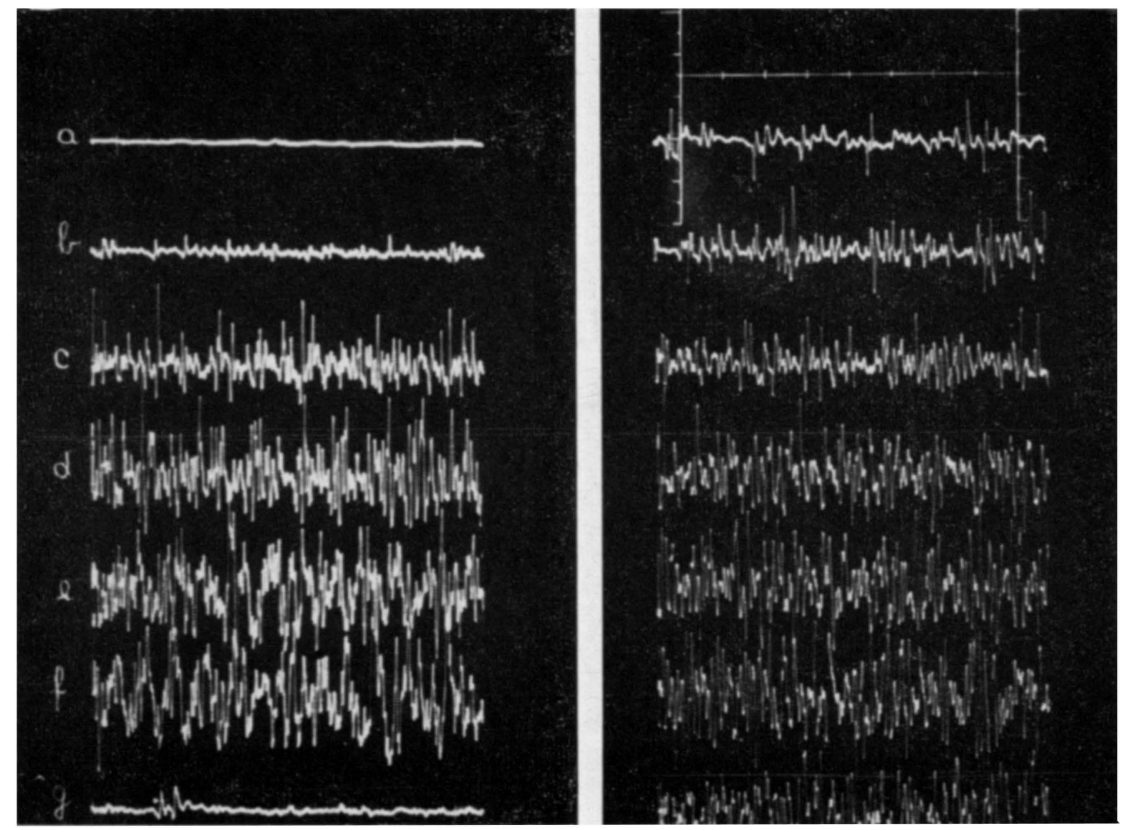

Fig. 2 - À esquerda, electromiograma de músculo reto medial normal...Em $a$, aspecto de traçado obtido com o músculo em repouso. Em b, início da contração do músculo. Em $c$, posição primária do olhar. Em d, posição intermediária entre a primária e a de adução máxima. Em e, o músculo está em contração máxima com o ôlho em adução completa. Em $f$, é mantido o esfôrço máximo de adução. Em g, potencial de ação isolado (200 $\mu \mathrm{V}$ por $\mathrm{cm}$ e $10 \mathrm{mseg}$ ). Comparar com o electromiograma ao lado. À direita, electromiograma do músculo reto medial deficitário do ôlho esquerdo na paciente A.C.P. Em a, aspecto normal de traçado obtido com o músculo em repouso. Em b, inicio da contraç̃o muscular. Em c, posição primária do olhar. Em $d$, posição intermediária entre a primária e a que seria de aducão máxima. Em e, a paciente executa esforços para aduzir ao máximo o ôlho esquerdo. Em $f$, a paciente continua sua tentativa de aduzir ao máximo o ôlho esquerdo. Em g, convergência normal (200 $\mu \mathrm{V}$ por $\mathrm{cm}$ e $10 \mathrm{mseg}$ ).

COMENTARIOS

Trata-se de caso de oftalmoplegia internuclear com manifestações clínicas bilaterais e assimétricas, uma vez que havia déficit de ambos os 
músculos reto mediais, embora mais acentuado à esquerda, nistagmo vertical bilateral no olhar para cima e nistagmo horizontal monocular do ôlho abduzido, mais acentuado ao olhar lateral para a direita. A adução na convergência estava conservada, o que permitiu caracterizar a síndrome como de tipo posterior 4, 6, ?.

As lesões responsáveis teriam afetado ambos os fascículos longitudinais mediais e estariam predominando de um dos lados. Não havia sinais de comprometimento de estruturas vizinhas no tronco cerebral. As lesões provàvelmente são de natureza desmielinizante e dependentes da neuranemia. Esta localização não é habitual nesta moléstia.

O electromiograma do RM esquerdo não mostrou qualquer especificidade e permitiu excluir lesão neurogênica ou do próprio músculo.

Tem sido referido, na paralisia internuclear ${ }^{1,2,5}$, aumento dos potenciais de ação do RM deficitário até um certo ponto em que, sùbitamente, êsse aumento cessa apesar do esfôrço do olhar no campo de ação daquele músculo.

A insuficiência da adução do RM é geralmente atribuída a uma paralisia supranuclear, sendo difícil o seu reconhecimento eletromiográfico ${ }^{1,2,5}$. Nestes casos as unidades motcras não são afetadas e sim a reciprocidade dos músculos extrínsecos oculares, sua atividade tônica e o padrão de descargas elétricas $1,2,3,5$.

\section{RESUMO}

E relatado um caso de oftalmoplegia internuclear, tipo posterior, com manifestações oculares bilaterais e assimétricas em paciente com mielose funicular. $\mathrm{O}$ diagnóstico da natureza da moléstia foi comprovado pela prova de absorção da vitamina $B_{12}$ radioativa marcada com ${ }^{57}$ Co (método de Schilling). Foram realizados três exames electromiográficos do músculo reto medial mais afetado (esquerdo), com intervalos de 45 a 90 dias, não tendo havido modificação dos traçados. O electromiograma nada mostrou de específico e permitiu excluir lesão neurogênica (paresia ou paralisia do $3 .^{\circ}$ nervo) e muscular pròpriamente dita (miopatia).

\section{SUMMARY}

\section{Internuclear ophtalmoplegia in a patient with subacute combined degeneration of the spinal cord}

A case of posterior internuclear ophthalmoplegia with bilateral and asymetric manifestations in a patient with subacute combined degeneration of the spinal cord is reported. The diagnosis of the spinal cord disease was made in clinical findings and proved by absorption of radioactive cyanocobalamin through the Schilling's urinary excretion test. The electromyogram of the left medial rectus muscle showed no signs of paresis such as are found in lower motor disease or myopathies. 


\section{REFERENNCIAS}

1. BREININ, G. M. - Electromyography, a tool in ocular and neurologic diagnosis: supranuclear mechanisms. Arch. Ophthalm. 59:177-187, 1958.

2. BREININ, G. M. - The Electrophysiology of Extraocular Muscles with Special Reference to Electromyography. Toronto Press, Toronto (Canada), 1962.

3. Carvalho, C. A. - Eletromiografia dos músculos extrínsecos do ôlho. Arq. brasil. Oftalm. 30:123-138, 1967.

4. COGAN, D. G.; KUBIK, C. S. \& SMITH, W. L. - Unilateral internuclear ophthalmoplegia. Arch. Ophthalm. 44:783-796, 1950.

5. ISCH, F. - Életcromyographie. Éditions Doin, Paris, 1963.

6. SMITH, J. L. \& COGAN, D. G. - Internuclear ophthalmoplegia. A review of fifty-eight cases. Arch. Ophthalm. 61:687-694, 1959.

7. WALSH, F. B. - Clinical Neuro-ophthalmology. Second edition. Williams \& Wilkins Co., Baltimore, 1957, págs. 248-250.

Clinica Neurológica - Faculdade de Medicina da Universidade de São Paulo Caixa Postal 3461 - Sĩo Paulo, SP, Brasil. 